\title{
POTENTIAL DISTRIBUTION AND EFFECTS OF CLIMATE CHANGE ON THE RISK OF SCORPION STING WITH ENDEMIC AND MEDICALLY IMPORTANT SCORPION ODONTOBUTHUS DORIAE THORELL, 1876 (ARACHNIDA: SCORPIONIDAE: BUTHIDAE) IN IRAN
}

\author{
Mahboubeh Sadat Hosseinzadeh
}

Department of Biology, Faculty of Science, University of Birjand, Birjand, Iran. Email: m.hosseinzadeh@birjand.ac.ir; m.hosseinzadeh.bio@gmail.com

\begin{abstract}
Article history
Received: 13 December 2019 accepted 15 September 2020
\end{abstract}

\section{Keywords:}

Venom; Iran; MaxEnt;

Zagros Mountains

\begin{abstract}
In this research, the MaxEnt modeling approach was used to distinguish the potential niche and distribution pattern of Odontobuthus doriae, a scorpion mainly endemic to central Iran. In aggregate, 47 occurrence records and five environmental variables were applied in the modeling of current and future periods. Central Iran was confirmed as the most suitable habitat for $O$. doriae, which approximately corresponds to its known distribution. Among the environmental variables, temperature seasonality and mean temperature of the coldest quarter were the most important driving factors. Interestingly, the current distribution of $O$. doriae completely corresponds to geographical limitations in the north and the west presented by the Alborz and Zagros Mountains, respectively. Future projection showed a distributional shift towards northern part of Iran. In the context of its medical importance, more studies on biology and ecology of $O$. doriae could help scientists to better inform, health care management activities.
\end{abstract}

\section{INTRODUCTION}

Scorpions are predatory animals belonging to the Arachnida (Phylum Arthropoda, Subphylum Chelicerata) with 2200 species (Lourenço 2015, 2018). They are distributed globally with the exception of Antarctica, and are especially prevalent in tropical and subtropical regions (Lourenço 2015, 2018).

So far, 18 scorpion families have been reported in the world (Soleglad and Fet 2003; Prendini and Wheeler 2005). Out of these, four families have reported from Iran, including Buthidae, Scorpionidae, Hemiscorpiidae and Diplocentridae (Lourenço 2015). These families comprise 20 genera encompassing 77 species (Mirshamsi et al. 2011, 2013; Navidpour et al. 2013; Azghadi et al. 2014; Kazemi and Sabatier 2019; Kovařík 2019; Kovař́k and Navidpour 2020).

The genus Odontobuthus Vachon, 1950, a member of family Buthidae, is found in the Rajasthan desert of western India, and the Indus River drainage of eastern Pakistan to the Tigris-Euphrates River drainage in Iraq (Lourenço and Pézier 2002; Lowe 2010; Mirshamsi et al. 2013). The genus contains six species: O. bidentatus (Lourenço and Pézier 2002), O. brevidigitus Lowe 2010, O. doriae (Thorell 1876), O. odonturus (Pocock 1897), O. tavighiae Navidpour, Soleglad, Fet and Kovarik 2013, and O. tirgari Mirshamsi, Azghadi, Navidpour, Aliabadian and Kovarik 2013 (Farzanpay 1987; Lowe 2010; Mirshamsi et al. 2011; Navidpour et al. 2013; Mirshamsi et al. 2013; Azghadi et al. 2014; Kazemi and Sabatier 2019). All of these species occur in Iran with the exception of $O$. brevidigitus which is distributed along the Batínah coast and foothills of the Al Hajar Mountains of northern Oman (Lowe 2010). According to some authors, Odontobuthus odonturus is present in Iran but Lowe (2010) disputes its occurrence in Iran (Vachon 1966; Farzanpay 1988; Mirshamsi et al. 2011; Nejati et al. 2014). Among the Iranian species of Odontobuthus, O. doriae is particularly important due to its medical application and widespread distribution (Jalali and Rahim 2014). Based on Hauke and Herzig (2017) and Ward et al. (2018), the genus of Odontobuthus in Iran comprises species with potent biotoxic and bioactive molecular compounds. Odontobuthus doriae distributed in western, southeastern, and central parts of Iran (Pocock 1900; Birula 1905; Farzanpay 1987; Lourenço and Pézier 2002; Lowe 2010; Navidpour et al. 2011). Toxicity of this scorpion's venom is high with a lethal dose (LD50) of $0.19 \mathrm{mg} / \mathrm{kg}$ for extracted neurotoxins injected into mice (Jalali and Rahim 2014; Fatani 2015; Motevalli Haghi and Dehghani 2017). Despite a high rate of scorpion stings in Iran only a few studies have been conducted on the most venomous scorpions in Iran (Jalali and Rahim 2014).

Ecological approaches to studying these scorpions provide more knowledge about their spatial distribution and help facilitate identification of suitable habitats, influential environmental factors and effective conservation programs, especially for endangered and endemic 
species (Guisan and Zimmermann 2000; Graham et al. 2004; Guisan and Thuiller 2005). One useful algorithm is ecological niche modeling (ENM), which estimates the relationship between characteristics such as environment, topography, distribution, and species occurrence and then identifies variables which limit the distribution of a particular species (Guisan and Zimmermann 2000; Graham et al. 2004; Guisan and Thuiller 2005; JiménezValverde et al. 2008). The popularity of ENMs is related to a need for useful information to manage conservation activities (Bulluck et al. 2006). Predictive models of potential geographic distributions are extensively used for a variety of applications in ecology, conservation and biogeography (Graham et al. 2004; Guisan and Thuiller 2005). Here, I am to estimate a potential distribution pattern, and to identify suitable habitat and limiting factors of the yellow scorpion distribution for future predictions so as to eventually provide more information about the ecology of the species to enable avoidance of encounters resulting in envenomation from stings.

\section{MATERIALS AND METHODS}

In this study, 47 occurrences of $O$. doriae were identified from field work and the literature (Vignoli and Crucitti 2005; Navidpour et al. 2011, 2019; Mirshamsi et al. 2013; Moradi et al. 2015; Jafari et al. 2015; Table 1). To avoid spatial auto-correlation, localities less than 10-kilometer in distance from each other were omitted (Merckx et al. 2011).

In total, 19 variables related to bioclimatic seasonality and annual trends of temperature and precipitation were downloaded from the WorldClim database (http://www. worldclim.org, Hijmans et al. 2005) for the present period. For future periods, predicted environmental factors were downloaded for i) the year 2070, ii) the average for 2061-2080, and iii) the representative concentration pathway (RCP) emission scenarios (8.5) available for GCMs (general circulation models). For future projections, CCSM4, MIROC5 and GISSE2-R were used (Hijmans et al. 2005). I chose the RCP 8.5 because it has shown that distribution pattern of species corresponds to intensive scenario with rising temperature approximately to $2.37-4.4{ }^{\circ} \mathrm{C}$ (Newth and Gunasekera 2018). All environmental layers have been extracted at a spatial resolution of 30 arc seconds (grid cells of $0.0083^{\circ}$ - approximately $1 \mathrm{~km}$ ). The mentioned layers have been clipped for Iran territory by ARCMAP 10.4.1. To achieve final map for RCP 8.5, I overlaid a prediction map from the Three GCM using DIVA-GIS.

Initially, correlations between all 19 environmental variables were estimated using Pearson's correlation coefficient in SPSS 16. Variables with correlation coef- ficients $>0.7$ were omitted from modeling. Then, five out of 19 environmental variables were chosen and used in this study including i) precipitation of the warmest quarter (Bio18), ii) annual precipitation (Bio12), iii) mean diurnal temperature range (Bio2), iv) temperature seasonality (bio4), and v) mean temperature of the coldest quarter (Bio 11).

Table 1. List of occurrence points of Odontobuthus doriae used in the study.

\begin{tabular}{|c|c|c|c|}
\hline Species & Longitude & Latitude & Source \\
\hline O. doriae & 57.190 & 30.123 & Navidpour et al. 2011 \\
\hline O. doriae & 56.588 & 30.795 & Navidpour et al. 2011 \\
\hline O. doriae & 56.217 & 30.520 & Navidpour et al. 2011 \\
\hline O. doriae & 55.094 & 30.028 & Navidpour et al. 2011 \\
\hline O. doriae & 55.094 & 30.028 & Navidpour et al. 2011 \\
\hline O. doriae & 55.093 & 30.47 & Navidpour et al. 2011 \\
\hline O. doriae & 52.477 & 31.181 & This study \\
\hline O. doriae & 54.104 & 29.094 & This study \\
\hline O. doriae & 50.876 & 32.454 & This study \\
\hline O. doriae & 53.446 & 35.590 & This study \\
\hline O. doriae & 49.166 & 36.139 & Moradi et al. 2014 \\
\hline O. doriae & 48.796 & 36.457 & Moradi et al. 2014 \\
\hline O. doriae & 48.383 & 36.693 & Moradi et al. 2014 \\
\hline O. doriae & 51.435 & 33.974 & This study \\
\hline O. doriae & 51.316 & 34.283 & This study \\
\hline O.doriae & 51.416 & 34.083 & This study \\
\hline O. doriae & 51.883 & 33.916 & This study \\
\hline O. doriae & 55.504 & 31.711 & Vignoli and Crucitti 2005 \\
\hline O. doriae & 54.252 & 32.310 & Vignoli and Crucitti 2005 \\
\hline O. doriae & 50.767 & 35.751 & Jafari et al. 2015 \\
\hline O. doriae & 48.215 & 37.389 & Jafari et al. 2015 \\
\hline O. doriae & 50.342 & 35.493 & Jafari et al. 2015 \\
\hline O. doriae & 49.511 & 36.447 & Jafari et al. 2015 \\
\hline O. doriae & 50.972 & 35.910 & Navidpour et al. 2019 \\
\hline O. doriae & 50.784 & 35.957 & Navidpour et al. 2019 \\
\hline O. doriae & 50.395 & 35.780 & Navidpour et al. 2019 \\
\hline O. doriae & 50.597 & 35.816 & Navidpour et al. 2019 \\
\hline O. doriae & 50.444 & 35.713 & Navidpour et al. 2019 \\
\hline O. doriae & 50.679 & 36.151 & Navidpour et al. 2019 \\
\hline O. doriae & 50.467 & 33.869 & Navidpour et al. 2019 \\
\hline O. doriae & 50.240 & 33.734 & Navidpour et al. 2019 \\
\hline O. doriae & 49.868 & 33.979 & Navidpour et al. 2019 \\
\hline O. doriae & 49.991 & 33.836 & Navidpour et al. 2019 \\
\hline O. doriae & 49.667 & 34.433 & Navidpour et al. 2019 \\
\hline O. doriae & 50.191 & 34.284 & Navidpour et al. 2019 \\
\hline O. doriae & 50.060 & 34.203 & Navidpour et al. 2019 \\
\hline O. doriae & 49.615 & 33.982 & Navidpour et al. 2019 \\
\hline O. doriae & 50.631 & 35.583 & Navidpour et al. 2019 \\
\hline O. doriae & 50.718 & 35.642 & Navidpour et al. 2019 \\
\hline O. doriae & 50.968 & 35.486 & Navidpour et al. 2019 \\
\hline O. doriae & 51.079 & 35.423 & Navidpour et al. 2019 \\
\hline O. doriae & 51.712 & 35.565 & Navidpour et al. 2019 \\
\hline O. doriae & 51.421 & 35.288 & Navidpour et al. 2019 \\
\hline O. doriae & 51.423 & 35.696 & Mirshamsi et al. 2013 \\
\hline O. doriae & 51.65 & 35.321 & Mirshamsi et al. 2013 \\
\hline O. doriae & 56.552 & 29.946 & Mirshamsi et al. 2013 \\
\hline O. doriae & 55.094 & 30.028 & Mirshamsi et al. 2013 \\
\hline
\end{tabular}


Maximum Entropy modeling (MaxEnt) involves algorithms that can be used for the prediction of a species' potential distribution. It is a machine-learning approach that estimates the likelihood of presence in a given cell on the basis of environmental features in that cell (Franklin 1995; Guisan and Thuiller 2005; Elith et al. 2006, 2010, 2011; Wisz et al. 2008). MaxEnt version 3.4.1 was applied with its default settings $(0.00001,500$ and 1 for Convergence threshold and maximum number of iterations, regularization multiplier respectively) (Phillips and Dudík 2008). The 'area under the receiver-operating characteristic curve' (AUC) was used for model evaluation, which surveys the ability of a model to distinguish between sites where a species is 'present' versus 'absent' (Phillips et al. 2006; Elith et al. 2006).

\section{RESULTS}

Current model performance was high with an average AUC of $0.817 \pm 0.129$ (Figure 1). The present model distribution map showed northern and central Iran as possessing highly

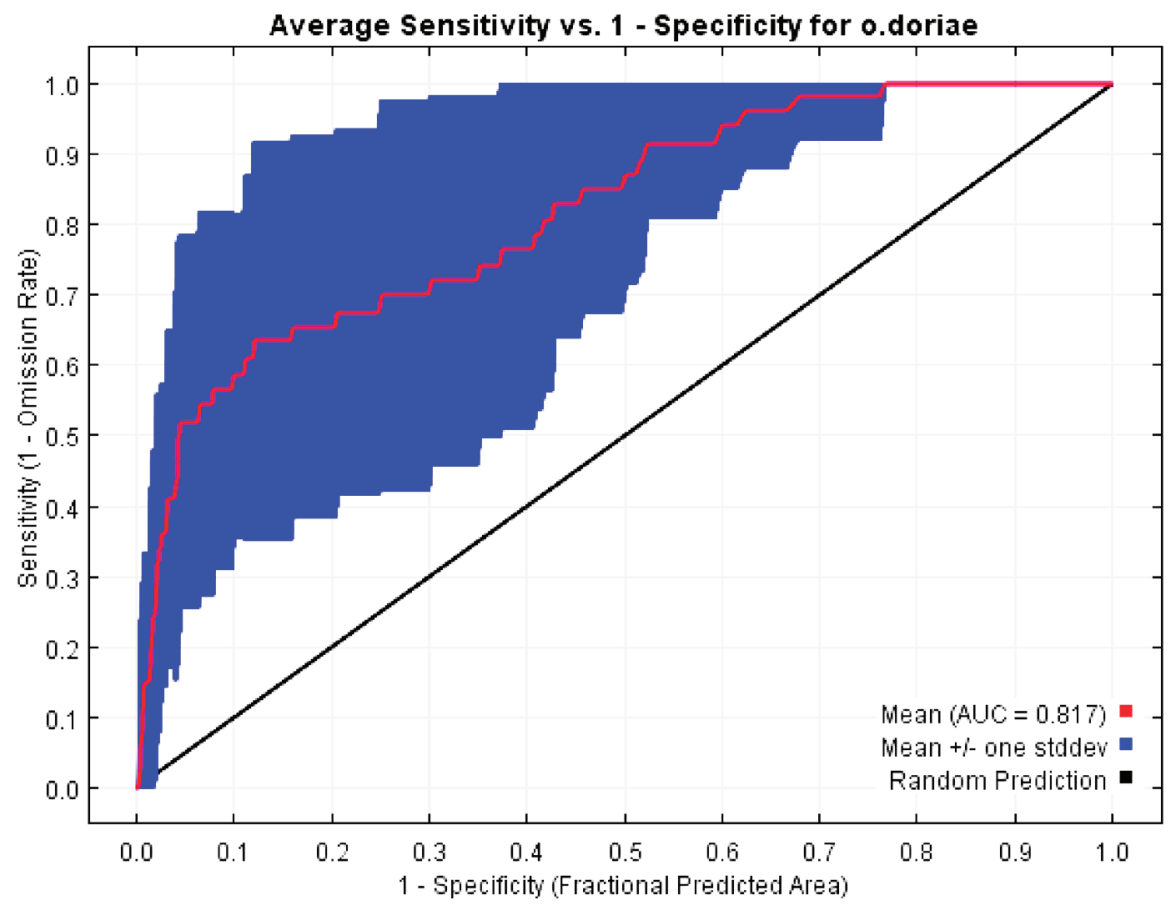

Figure 1. The graph of the area under the receiver operating characteristic (ROC) curve for Odontobuthus doriae's habitat suitability model. The red (training) line shows the "fit" of the model to the training data. The blue (testing) line indicates the fit of the model to the testing data and is the real test of the model's predictive power.

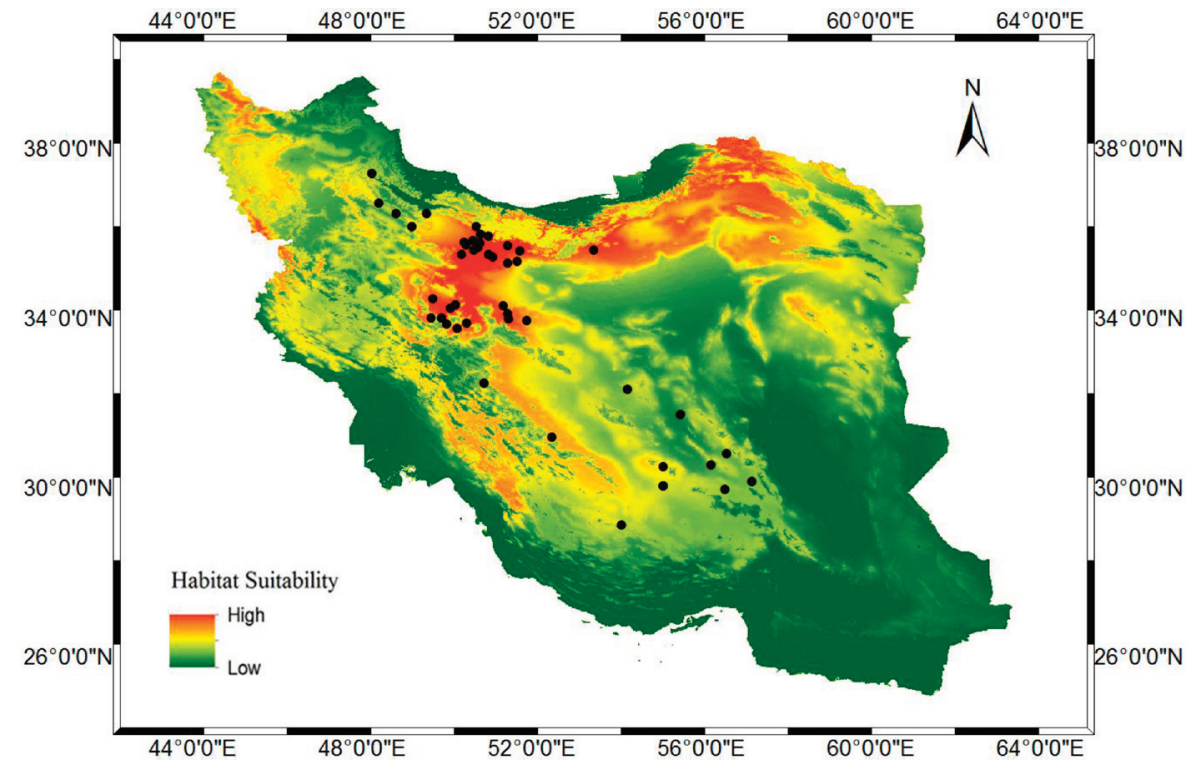

Figure 2. Potential distribution of Odontobuthus doriae resulting from the best-fitting MaxEnt model. 


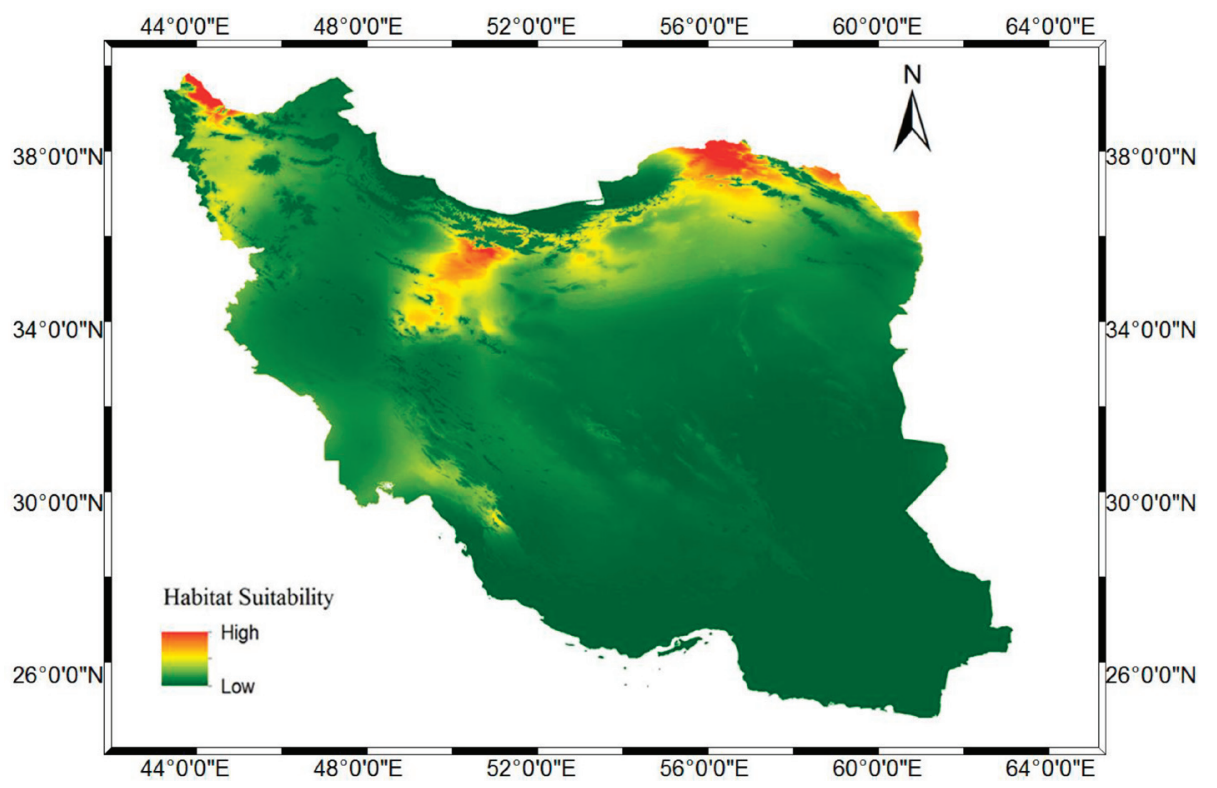

Figure 3. Future potential distribution of Odontobuthus doriae under scenario RCP 8.5.

suitable habitat for $O$. doriae (Figure 2). The southern part in which the species is distributed showed although there was available habitat for yellow scorpion it was not optimal. Future prediction revealed a more limited distribution of habitat would be available than the present projection. It indicated a clear trend of the $O$. doriae distribution retreating towards the northern part of Iran (Figure 3).

Among the environmental variables, temperature seasonality was the most important determinant with a $32.1 \%$ contribution, followed by precipitation during the warmest quarter of the year (Bio18) with a $24.4 \%$ contribution to the modelled distribution (Table 2).

Table 2. Percentages of contributions of variables included in the best-fitting distribution model for Odontobuthus doriae.

\begin{tabular}{|l|c|}
\hline \multicolumn{1}{|c|}{ Variable } & $\begin{array}{c}\text { Variable } \\
\text { contribution }\end{array}$ \\
\hline Temperature seasonality (bio4) & 32.1 \\
\hline Precipitation of the warmest quarter (Bio18) & 24.4 \\
\hline Mean temperature of coldest quarter (bio 11) & 21.6 \\
\hline Annual precipitation (Bio12) & 15.3 \\
\hline Mean diurnal temperature range (Bio2) & 6.6 \\
\hline
\end{tabular}

\section{DISCUSSION}

The distribution of $O$. doriae is limited to northern, central and some southern regions of Iran. Geographically, there are two high mountain ranges in Iran; the Alborz, from northwest to northeast and the Zagros which traverse from northwest to southeast, thereby creating an amphitheater around the plateau (Fisher 1968). The Zagros Mountains form a geographic barrier which sepa- rates central from western Iran and gives rise to different climates on either side of the highland, and in so doing plays an important role in speciation, isolation, diversification and endemism (Fisher 1968; Rastegar-Pouyani et al. 2010). Interestingly, the distribution of the yellow scorpion precisely corresponds to the geographical limitations imposed in the north and the west by the Alborz and Zagros Mountains, respectively. In addition, some regions of the known distribution pattern of the species have suboptimal habitat most likely delineating the marginal extremes of the distribution compared with the highly suitable habitat in the northern and central parts of Iran. The results suggest that population density of the species in the southern parts might be lower than in highly suitable habitat in northern parts of distribution and as, the species is fossorial, differences in soil and substrate type among the regions might be affecting habitat suitability. Formerly, the range distribution of the species was larger than today because recent studies have shown that some isolated populations of Odontobuthus that were previously attributed to $O$. doriae, actually belong to other species. The isolated populations from Khuzestan Province in western Iran, belong to O. bidentatus which is separated from central Iran by the Zagros Mountains (Lourenço and Pézier 2002). In addition, populations in southern and coastal regions bordering the Persian gulf comprise $O$. tavighiae which is separated from $O$. doriae by the southeastern slope of the Zagros Mountains. Finally a population in eastern Iran recently identified as $O$. tirgari is isolated from $O$. doriae by the severe and hot Iranian desert area named Dasht-e-Kavir (Navidpour et al. 2013; Mirshamsi et al. 2013). Based on Lowe (2010), these disjointed geographical distributions of the Odontobuthus populations related to the Miocene/Pliocene paleoclimatic and vicariance events 
which might have affected the distributions in the Iranian Plateau (Lowe 2010).

Medically, the risks associated with a scorpion sting can be critical in terms of community health in many Middleeast countries because of the severity and wide range of clinical effects from envenomation. Biodiversity among Iranian scorpions is very high (Mirshamsi et al. 2011; Kazemi and Sabatier 2019) placing Iran among the world's hotspots for instances of humans being stung (Ward et al. 2018). The majority of stings result in cardiotoxicity, neurotoxicity and respiratory dysfunction (Isbister et al. 2003; Bawaskar and Bawaskar 2012). Since O. doriae is a potentially dangerous scorpion due to the potency of its venom and has a wide spatial distribution that increases the likelihood of human encounters, it is vitally important that Iran's medical health system can provide antivenom and the other treatment medications.

The finding that temperature was the most important factor of distribution modeling is consistent with Mirshamsi et al. (2013), who concluded that temperature and precipitation are effective variables for species modelling of Mesobuthus eupeus and M. phillipsii. Another study showed that mean temperature of the wettest quarter (Bio8) and precipitation during the coldest quarter (Bio19) affected the desirability of habitat for Odontobuthus doriae and Scorpio maurus, receptively (Haghani et al. 2020). In addition, MaxEnt modeling showed that the most important environmental factor influencing the distribution of Hemiscorpius lepturus was the maximum temperature of the warmest month (Bio5) (Hanafi-Bojd et al. 2020). According to Chowell et al. (2005), climatic conditions, dryness and heat are factors that increase the threat of being stung by a scorpion. The risk of a scorpion sting from $O$. doriae was significantly higher than from being stung by other species among urban and rural envenomation patients. Moreover, Ebrahimi et al. (2017) suggested that the activity of scorpions increased from January to the end of May. Basically, scorpions are poikilothermic (cold-blooded) arthropods and so are more active during warmer months most likely encompassing their reproduction period (Molaee et al. 2014). Biologically, climatic factors and geographic locations affect scorpion sting intensity (Ozkan et al. 2008). Based on Ebrahimi et al. (2017), temperature is positively associated with the prevalence of scorpion sting cases. Finally, more studies on the biology and ecology of $O$. doriae should help scientists to better inform the management of medical heath and conservation activities.

\section{ACKNOWLEDGMENTS}

I am most grateful to Seyed Mahdi Kazemi for providing helpful comments on the preliminary draft of the manuscript and some informative points about the species. I am also appreciative of Dr. Steven C. Anderson for editing the English expression in a preliminary draft of this manuscript.

\section{REFERENCES}

Azghadi, S., O. Mirshamsi, S. Navidpour, and M. Aliabadian. 2014. Scorpions of the genus Odontobuthus Vachon, 1950 (Scorpiones: Buthidae) from Iran: Phylogenetic relationships inferred from mitochondrial DNA sequence data. Zoology in the Middle East 60: 169-179.

Bawaskar, H. S. and P. H. Bawaskar. 2012. Scorpion sting: update. Journal of the Association of Physicians of India 60 (1): 46-55.

Birula, A. A. 1905. Beiträge zur Kenntnis der Skorpionenfauna Persiens (3. Beitrag). Bulletin de l'Académie Impériale des Sciences de St. Pétersbourg, Sér. 5 (23): 119-148.

Bulluck, L., E. Fleishman, C. Betrus, and R. Blair. 2006. Spatial and temporal variations in species occurrence rate affect the accuracy of occurrence models. Global Ecology and Biogeography 15: 27-38.

Chowell, G., J. M. Hyman, P. Diaz-Duenas, and N. W. Hengartner. 2005. Predicting scorpion sting incidence in an endemic region using climatological variables. International Journal of Environmental Health Research 15: 425-435.

Ebrahimi, V., E. Hamdami, M. D. Moemenbellah-Fard, and S. E. Jahromi. 2017. Predictive determinants of scorpion stings in a tropical zone of south Iran: use of mixed seasonal autoregressive moving average model. Journal of venomous animals and toxins including tropical diseases 23 (1): 39.

Elith, J., C. H. Graham, R. P. Anderson, M. Dudík, S. Ferrier, A. Guisan, R. J. Hijmans, F. Huettmann, J. R. Leathwick, A. Lehmann, J. Li, L. G. Lohmann, B. A. Loiselle, G. Manion, C. Moritz, M. Nakamura, Y. Nakazawa, J. Overton, A. T. Peterson, S. J. Phillips, K. S. Richardson, R. Scachetti-Pereira, R. E. Schapire, J. Soberón, S. Williams, M. S. Wisz, and N. E. Zimmermann. 2006. Novel methods improve predictions of species distribution from occurrence data. Ecography 29: 129-151.

Elith, J., M. Kearney, and S. Phillips. 2010. The art of modelling range-shifting species. Methods in Ecology and Evolution 1: 330-342.

Elith, J., S. J. Phillips, T. Hastie, M. Dudík, Y. E. Chee, and C. J. Yates. 2011. A statistical explanation of MaxEnt for ecologists. Diversity and Distributions 17: 43-57.

Farzanpay, R. 1987. Knowing scorpions. No. 312, Biology 4. Tehran: Central University Publications, 231 pp. (In Persian). 
Farzanpay, R. 1988. A catalogue of the scorpions occurring in Iran, up to January 1986. Revue Arachnologique 8: $33-44$.

Fatani, A. J. 2015. Snake venoms and scorpion venom research in the Middle East: A Review. Clinical Toxicology in Asia Pacific and Africa: 327-355.

Fisher, W. B. 1968. Physical geography. In The Cambridge History of Iran 1, the Land of Iran, edited by Fisher W. B., 3-111. London: Cambridge University Press.

Franklin, J. 1995. Predictive vegetation mapping: geographic modeling of biospatial patterns in relation to environmental gradients. Progress in Physical Geography 19: 474-499.

Graham, C. H., S. Ferrier, F. Huettman, C. Moritz and A. T. Peterson. 2004. New developments in museumbased informatics and application in biodiversity analysis. Trends in Ecology and Evolution 19: 497-503.

Guisan, A., and N. E. Zimmermann. 2000. Predictive habitat distribution models in ecology. Ecological Modelling 135: 147-186.

Guisan, A., and W. Thuiller. 2005. Predicting species distribution: offering more than simple habitat models. Ecology Letters 8: 993-1009.

Haghani, A., M. Khoobdel, R. Dehghani, A. Adibzadeh, H. Sobati, and M. Aliabadian. 2020. Ecological modeling and distribution analysis of digger scorpions: Odontobuthus doriae, Odonthubutus bidentatus (Scorpiones: Buthidae) and Scorpio maurus (Scorpiones: Scorpionidae) in Iran using the maximum entropy method. Applied Entomology and Zoology 55 (1):17-24.

Hanafi-Bojd, A. A., M. Sharififard, E. Jahanifard, S. Navidpour, and B. Vazirianzadeh. 2020. Presence probability of Hemiscorpius lepturus Peters, 1861 using maximum entropy approach in the western areas of Zagros Mountains, Iran. Vetrinary World 13 (2): 296-303.

Hauke, T. J., and V. Herzig. 2017. Dangerous arachnids Fake news or reality? Toxicon 138: 173-183.

Hijmans, R. J., S. E. Cameron, J. L. Parra, P. G. Jones, and A. Jarvis. 2005. Very high resolution interpolated climate surfaces for global land areas. International Journal of Climatology: A Journal of the Royal Meteorological Society 25 (15): 1965-1978.

Isbister, G. K., A. Graudins, J. White, and D. Warrell. 2003. Antivenom treatment in arachnidism: antivenoms. Journal of Toxicology: Clinical Toxicology 41 (3): 291-300.

Jafari, N., M. Moradi, P. M. Gharakhloo, and A. Akbari. 2015. Scorpion Fauna of Alborz Province, Iran (Arachnida: Scorpiones). Journal of Applied Biological Sciences 9 (2): 83-85.

Jalali, A., and F. Rahim. 2014. Epidemiological review of scorpion envenomation in Iran. Iranian Journal of Pharmaceutical Research 13: 743-756.

Jiménez $\square$ Valverde, A., J. M. Lobo, and J. Hortal. 2008. Not as good as they seem: the importance of concepts in species distribution modelling. Diversity and distributions 14 (6): 885-890.

Kazemi, S. M., and J. M. Sabatier. 2019. Venoms of Iranian Scorpions (Arachnida, Scorpiones) and Their Potential for Drug Discovery. Molecules 24: 2670.

Kovařík, F. 2019. Taxonomic reassessment of the genera Lychas, Mesobuthus, and Olivierus, with descriptions of four new genera (Scorpiones: Buthidae). Euscorpius 288: 1-27.

Kovařík, F., and S. Navidpour. 2020. Six new species of Orthochirus Karsch, 1892 from Iran (Scorpiones: Buthidae). Euscorpius 31: 1-41.

Lourenço, W. R. 2015. Scorpion diversity and distribution: Past and present patterns. In Scorpion Venoms. Toxinology, edited by Gopalakrishnakone, P., E. F. Schwartz, L. D. Possani, and R. C. Rodríguez de la Vega. Dordrecht: Springer Science \& Business Media.

Lourenço, W. R. 2018. The evolution and distribution of noxious species of scorpions (Arachnida: Scorpiones). Journal of Venomous Animals and Toxins including Tropical Diseases 24: 1.

Lourenço, W. R., and A. Pézier. 2002. Taxonomic consideration of the genus Odontobuthus Vachon (Scorpiones: Buthidae), with description of a new species. Revue Suisse de Zoologie 109: 115-125.

Lowe, G. 2010. A new species of Odontobuthus (Scorpiones: Buthidae) from northern Oman. Euscorpius 96: 1-22.

Merckx, B., M. Steyaert, A. Vanreusel, M. Vincx, and J. Vanaverbeke. 2011. Null models reveal preferential sampling, spatial autocorrelation and overfitting in habitat suitability modelling. Ecological Modelling 222: 588-597.

Mirshamsi, O. 2013. Ecological niche modeling of two scorpion species Mesobuthus eupeus (C. L. Koch, 1839) and M. phillipsii (Pocock, 1889) from the Iranian Plateau and Zagros region (Arachnida: Scorpiones). Euscorpius (154): 1-10.

Mirshamsi, O., A. Sari, and S. Hosseinie. 2011. History of study and checklist of the scorpion fauna (Arachnida: Scorpiones) of Iran. Progress in Biological Sciences 1: 16-28.

Mirshamsi, O., S. Azghadi, S. Navidpour, M. Aliabadian, and F. Kovař́k. 2013. Odontobuthus tirgari sp. nov. (Scorpiones, Buthidae) from the eastern region of the Iranian Plateau. Zootaxa 3731: 153-170.

Molaee, S. M., K. A. Ahmadi, B. Vazirianzadeh, and S. A. Moravvej. 2014. A climatological study of scorpion sting incidence from 2007 to 2011 in the Dezful area of Southwestern Iran, using a time series model. Journal of Insect Science 14 (1): DOI: 10.1093/jisesa/ieu013.

Moradi, M., E. A. Yağmur, P. M. Gharakhloo, and F. Ahmadi. 2015. Scorpion Fauna of Zanjan Province, Iran (Arachnida: Scorpiones). Journal of Applied Biological Sciences 9 (1): 11-14.

Motevalli Haghi, F., and R. Dehghani. 2017. A Review of 
Scorpions Reported in Iran. Journal of Mazandaran University of Medical Sciences 27 (151): 213-226.

Navidpour, S., F. Kovař́ík, M. E. Soleglad, and V. Fet. 2019. Scorpions of Iran (Arachnida, Scorpiones). Part X. Alborz, Markazi and Tehran Provinces with a description of Orthochirus carinatus sp. n. (Buthidae). Euscorpius 276: 1-20.

Navidpour, S., M. E. Soleglad, V. Fet, and F. Kovařík. 2013. Scorpions of Iran (Arachnida, Scorpiones). Part IX. Hormozgan Province, with a description of Odontobuthus tavighiae sp. n. (Buthidae). Euscorpius 170: 1-29.

Navidpour, S., M. Ezatkhah, F. Kovařík, M. E. Soleglad, and V. Fet. 2011. Scorpions of Iran (Arachnida: Scorpiones). Part VII. Kerman Province. Euscorpius 131: 1-32.

Nejati, J., E. Mozafari, A. Saghafipour, and M. Kiyani. 2014. Scorpion fauna and epidemiological aspects of scorpionism in southeastern Iran. Asian Pacific Journal of Tropical Biomedicine 4: S217-S221.

Newth, D., and D. Gunasekera. 2018. Projected Changes in Wet-Bulb Globe Temperature under Alternative Climate Scenarios. Atmosphere 9 (5): 187.

Ozkan, O., R. Uzun, S. Adiguzel, Y. Cesaretli, and M. Ertek. 2008. Evaluation of scorpion sting incidence in Turkey. Journal of Venomous Animals and Toxins including Tropical Diseases 14 (1): 128-140.

Phillips, S. J., and M. Dudík. 2008. Modeling of species distributions with MaxEnt: new extensions and a comprehensive evaluation. Ecography 31: 161-175.

Phillips, S. J., R. P. Anderson, and R. E. Schapire. 2006. Maximum entropy modeling of species geographic distributions. Ecological Modelling 190: 231-259.

Pocock, R. I. 1900. Arachnida. In The Fauna of British India, including Ceylon and Burma, edited by Blanford, W. T., xii: 279. Taylor and Francis, London: Published under the authority of the Secretary of State for India in Council.
Prendini, L., and W. C. Wheeler. 2005. Scorpion higher phylogeny and classification, taxonomic anarchy, and standards for peer review in online publishing. Cladistics 21: 446-494.

Rastegar-Pouyani, E., N. Rastegar Pouyani, S. Kazemi Noureini, U. Joger, and M. Wink. 2010. Molecular phylogeny of the Eremias persica complex of the Iranian plateau (Reptilia:Lacertidae), based on mtDNA sequences. Zoological Journal of the Linnaean Society 158: 641-660.

Soleglad, M. E., and V. Fet. 2003. High-level systematics and phylogeny of the extant scorpions (Scorpiones: Orthosterni). Euscorpius 11: 1-175.

Stocker, T. F., D. Qin, G. K. Plattner, M. Tignor, S. K. Allen, J. Boschung, A. Nauels, Y. Xia, V. Bex, and P. M. Midgley. 2013. The Physical Science Basis. Contribution of Working Group I to the Fifth Assessment Report of the Intergovernmental Panel on Climate Change (IPCC). Cambridge, United Kingdom and New York, NY, USA: Cambridge University Press, 1535 pp.

Vachon, M. 1966. Liste des scorpions connus en Egypte, Arabie, Israël, Liban, Syrie, Jordanie, Turquie, Irak, Iran. Toxicon 4: 209-218.

Vignoli, V., and P. Crucitti. 2005. Notes on the scorpion diversity (Arachnida, Scorpiones) of the Yazd province, central Iran. Acta Musei Moraviae, Scientiae biologicae (Brno) 90: 1-11.

Ward, M. J., S. A. Ellsworth, and G. S. Nystrom. 2018. A global accounting of medically significant scorpions: Epidemiology, major toxins, and comparative resources in harmless counterparts. Toxicon 151: 137-155.

Wisz, M. S., R. J Hijmans, J. Li, A. T. Peterson, C. H. Graham, and A. Guisan. 2008. Effects of sample size on the performance of species distribution models. Diversity and Distributions 14: 763-773. 